information on surveillance and prevention of occupational infections and injuries; and to identify areas for future research.

These broad objectives should interest a large target audience, including not only hospital epidemiologists and infection control practitioners, but also quality improvement professionals, hospital administra- tors, surgeons, intensivists, and microbiologists.

The conference format will include symposia, scientific sessions, poster sessions, and industry exhibits. Original scientific contributions will be solicited actively. Abstract forms, registration forms, and housing forms will be included in the preliminary program.

\title{
SHEA Membership List Available
}

A SHEA membership list is available for individuals or organizations who want to target mailings to hospital epidemiologists and other infectious disease specialists. The costs for a one-time mailing list are as follows: a commercial business,
$\$ 500$; a not-for-profit organization, $\$ 150$; and a member using the list for research purposes, $\$ 50$. To order the list, contact SHEA Executive Director, 875 Kings Highway, Suite ZOO, West Deptford, NJ 08096. Telephone (609) 845-1636.
The chair and co-chair for this exciting event are Drs. C. Glenn Mayhall and John P. Burke, respectively. For further information, please contact SHEA, 875 Kings Highway, Suite 200, West Deptford, NJ 08096. Telephone (609) 845-1636.

Brief items of interest for the SHEA Newsletter may be sent to Robert A. Weinstein, MD, SHEA Newsletter Editor, Division of Infectious Diseases, Michael Reese Hospital, Lake Shore D rive at 31st St., Chicago, IL 60616. Copy must be typed, doublespaced, and may not exceed five pages. 


\title{
MEMBERSHIP APPLICATION
}

\section{THE SOCIETY FOR HOSPITAL EPIDEMIOLOGY OF AMERICA}

\author{
Please Print Clearly
}

Name:

Degree:

M.D.

Ph.D.

Other:

Title in Hospital Epidemiology:

Institution(s)

Name \& Address:

\begin{tabular}{lll}
\hline City & State & Zip Code
\end{tabular}

Business telephone:

(

F ax: (_ $)$ -

No. of Bequ: Category: Non-Teaching

Teaching

Home Address:

\begin{tabular}{lll}
\hline City & State & Zip Code
\end{tabular}

Home Telephone: (__)-

Indicate preferred address for membership directory:

Home Business

MEMBERSHIP FEE: (Non-U.S. members pay with draft for U.S. dollars)

Active Membership (Calendar year dues \$851

Associate Membership (Calendar year dues \$35)

Membership Fee includes subscription to the Society's official journal, Infection Control and Hospital Epidemiology.

MAKE CHECKS PAYABLE TO:

Send Application and Remittance To:
The Society for Hospital Epidemiology of America

SHEA MEMBERSHIP

875 Kings Highway, Suite 200

West Deptford. NJ 08096 

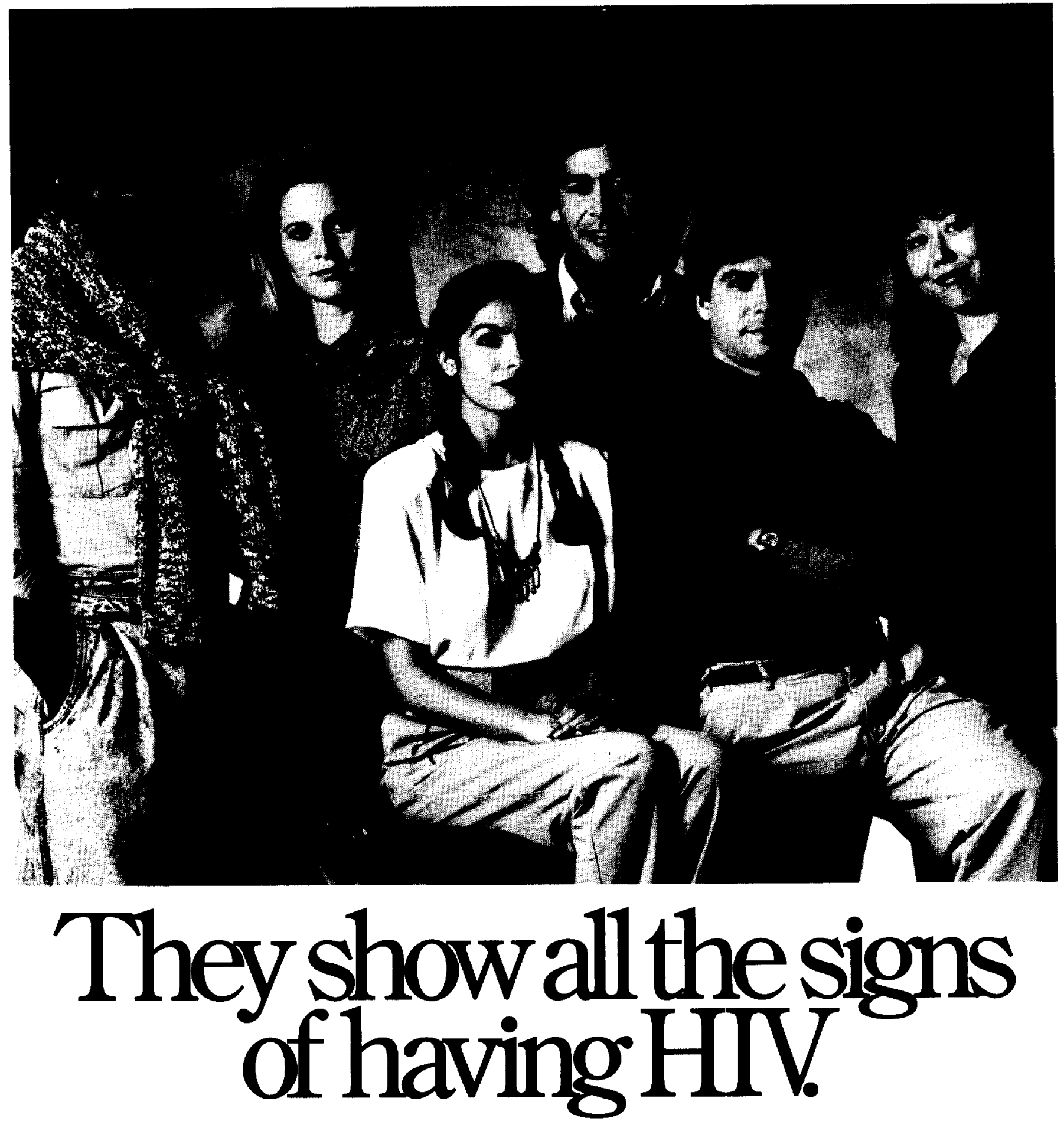

There aren't any you can see. The truth is, there is absolutely no way to tell from outward appearance who is infected with HIV, the virus that causes AIDS. So don't fool yourself.

How you act will determine your risk for HIV infection. There are some general rules. Never share drug needles or syringes. And unless you're sure your sex partner isn't infected, don't take a chance. Or at least use a latex condom, correctly, every single time you have sex.

Know how to determine your risk for HIV and AIDS. There is help available. Call your State or local AIDS hotline, or the National AIDS Hotline at 1-800-342-AIDS. Call 1-800-243-7889 (TTY) for deaf access.

AMERICA
RESPONISS
TO A I DS

HIV is the virus that causes AIDS.

Department of Health \& Human Services. Public Health Service, Centers for Disease Control. 